OPEN ACCESS

Edited by:

Helan Xu,

Jiangnan University, China

Reviewed by:

Hongliang Kang,

Institute of Chemistry (CAS), China

Kun $\mathrm{Hu}$,

Beijing Institute of Graphic

Communication, China

Shaoqing Cui,

The University of Tennessee,

United States

${ }^{*}$ Correspondence:

Liran Zhang

20180022@bift.edu.cn

Jianwei Cao

jwcao@ipe.ac.cn

Specialty section:

This article was submitted to

Polymeric and Composite Materials,

a section of the journal

Frontiers in Materials

Received: 04 October 2021 Accepted: 21 December 2021 Published: 08 February 2022

Citation:

Du W, Zhang L, Zhang C, Cao J, Wang D, Li H, Li W and Zeng J (2022) Green and Highly Efficient Wool Keratin

Extraction by Microwave

Induction Method.

Front. Mater. 8:789081

doi: 10.3389/fmats.2021.789081

\section{Green and Highly Efficient Wool Keratin Extraction by Microwave Induction Method}

\author{
Wenqian Du ${ }^{1,2}$, Liran Zhang ${ }^{1,2 *}$, Changhuan Zhang ${ }^{1}$, Jianwei Cao ${ }^{3 *}$, Dongmin Wang ${ }^{2}$, \\ Hongwei $L i^{1}$, Wenxia $L^{1}{ }^{1}$ and Jinling Zeng ${ }^{1}$
}

${ }^{1}$ Beijing Key Laboratory of Clothing Materials R\&D and Assessment, Beijing Engineering Research Center of Textile Nanofiber, Beijing Institute of Fashion Technology, Beijing, China, ${ }^{2}$ Department of Chemical Engineering, China University of Mining and Technology, Beijing, China, ${ }^{3}$ Institute of Process Engineering, Chinese Academy of Sciences, Beijing, China

Keratin is a plentiful and renewable fibrous protein resource found in nature, but a great deal of keratin-containing waste causes environmental problems, especially wool waste, which accounts for the majority. A green and efficient extraction method of keratin based on microwave induction method was studied. Compared with traditional thermal induction, the extraction time was shortened by half, and the dissolution rate of the wool was improved. The effects of the above two methods on the size, structure, crystallinity, and thermal stability of wool keratin were studied by a series of analysis methods [e.g., attenuated total reflectance Fourier transform infrared spectrometry (ATRFTIR), Raman spectroscopy, X-ray diffraction spectroscopy (XRD), dynamic light scattering (DLS), thermogravimetric analysis (TG), and so on]. The results showed that under microwave irradiation, the disulfide bonds were destroyed greatly, and the secondary structure changed significantly, which was beneficial to obtain wool keratin with low crystallinity and small particle size.

Keywords: Wool keratin, microwave induction, conventional thermal induction, secondary structure, disulfide bonds

\section{INTRODUCTION}

Keratin is a rich and renewable fibrin resource found in nature, which is the main component of wool, hair, feathers, nails, and horns (Vasconcelos et al., 2008; Shavandi et al., 2017a). Every year, more than 5 million tons of keratin-containing waste resources are produced in the world. These wastes come from hair, feathers, and horns of slaughterhouses, inferior raw hair, and by-products of wool fibers produced by textile processing in recycling stations (Wang et al., 2016; Shavandi et al., 2017b). Among these waste streams, wool waste is the majority. As keratin-containing wastes are not effectively utilized, this results in a significant loss of resources, with a corresponding potential of secondary ecological pollution to the environment (Zoccola et al., 2012; Khumalo et al., 2020). Recently, the comprehensive utilization of keratin has garnered more and more attention in areas, such as biological, medical, and packing applications (Aluigi et al., 2008a; Dias et al., 2010; Hill et al., 2010; Mori and Hara, 2018; Wu et al., 2018). The recovery and utilization of keratin have important economic, social, and ecological benefits, which open up new opportunities for the recovery and utilization of waste wool resources and can further broaden the application of keratin in engineering materials.

Wool is composed of about $95 \%$ keratin, containing 7-20 mol\% cysteine residues (Shavandi et al., 2017a). Most cysteines in keratin are located at the end of the protein, and two cysteines form 
TABLE 1 | Methods to extract and dissolve keratins from different biomaterials.

\begin{tabular}{|c|c|c|c|c|c|}
\hline Methods & Reference & Biomaterials & Treatment condition & Aim & Results \\
\hline \multirow[t]{7}{*}{ Chemical methods } & $\begin{array}{l}\text { Vasconcelos et al. } \\
\text { (2008) }\end{array}$ & Wool & $\begin{array}{l}8 \mathrm{M} \text { urea, } 0.2 \mathrm{M} \mathrm{SDS} \text {, and } 0.5 \mathrm{M} \mathrm{Na}_{2} \mathrm{~S}_{2} \mathrm{O}_{5} \text { at } 100^{\circ} \mathrm{C} \\
\text { for } 30 \mathrm{~min}\end{array}$ & Film preparation & $10 \%$ \\
\hline & $\begin{array}{l}\text { Yamauchi et al. } \\
\text { (1996) }\end{array}$ & Wool & $\begin{array}{l}7 \mathrm{M} \text { urea, SDS }(2 \%, \mathrm{w} / \mathrm{v}) \text {, and 2-mercaptoethanol } \\
(5 \%, \mathrm{v} / \mathrm{v}) \text { at } 50^{\circ} \mathrm{C} \text { for } 12 \mathrm{~h}\end{array}$ & Film preparation & $48 \%$ \\
\hline & $\begin{array}{l}\text { Nakamura et al. } \\
(2002)\end{array}$ & $\begin{array}{l}\text { Hair, wool, chicken } \\
\text { feather, human nail }\end{array}$ & $\begin{array}{l}25 \mathrm{mM} \text { Tris- } \mathrm{HCl}, 2.6 \mathrm{M} \text { thiourea, } 5 \mathrm{M} \text { urea, } 5 \%(\mathrm{v} / \mathrm{v}) \\
\text { 2-mercaptoethanol at } 50^{\circ} \mathrm{C} \text { for } 1-3 \text { days, and } \mathrm{pH} \\
=8.5\end{array}$ & Extraction & $67-85 \%$ \\
\hline & $\begin{array}{l}\text { Zoccola et al. } \\
\text { (2009) }\end{array}$ & Wool & $\begin{array}{l}8 \mathrm{M} \text { urea, } 0.14 \mathrm{M} \mathrm{DTT}, 5 \mathrm{mM} \text { Tris, } \mathrm{pH}=8.6 \text { at } 65^{\circ} \mathrm{C} \\
\text { for } 2 \mathrm{~h}\end{array}$ & Extraction & $50 \%$ \\
\hline & Poole et al. (2011) & Feather & $50 \mathrm{~g} / \mathrm{L} \mathrm{Na} \mathrm{N}_{2}$ solution at $30^{\circ} \mathrm{C}$ for $24 \mathrm{~h}$ & Bio-polymer & $62 \%$ \\
\hline & Tonin et al. (2007) & Wool fibers & $\begin{array}{l}8 \mathrm{M} \text { urea, } 0.5 \mathrm{M} \text { sodium bisulfate, the weight ratio of } \\
\mathrm{SDS} / \mathrm{wool}=0.6 \text { at } 65^{\circ} \mathrm{C} \text { for } 5 \mathrm{~h} \text { and } \mathrm{pH}=6.5\end{array}$ & Film preparation & $33 \%$ \\
\hline & Ji et al. (2014) & Feather & $\begin{array}{l}20 \mathrm{wt} \% \text { water, } 10 \mathrm{wt} \% \mathrm{Na}_{2} \mathrm{SO}_{3} \text { at } 90^{\circ} \mathrm{C} \text { for } 60 \mathrm{~min} \text {, } \\
\text { and the weight ratio of liquid/feather }=20\end{array}$ & $\begin{array}{l}\text { Dissolution and } \\
\text { extraction }\end{array}$ & $\begin{array}{l}\text { Dissolution rate: } 96.7 \% \text {; } \\
\text { Extraction yield: } 75.1 \%\end{array}$ \\
\hline \multirow[t]{4}{*}{$\begin{array}{l}\text { Physicochemical } \\
\text { methods }\end{array}$} & $\begin{array}{l}\text { Zoccola et al. } \\
\text { (2012) }\end{array}$ & Wool & $\begin{array}{l}\text { Microwave-assisted hydrolysis at } 150-180^{\circ} \mathrm{C} \text { for } \\
60 \mathrm{~min} \text {, mass of fiber/water rate of } 1: 5\end{array}$ & Extraction & $10-60 \%$ \\
\hline & Zhao et al. (2012) & Feathers & $\begin{array}{l}\text { HDSF treatment with the phosphate buffer }(0.01 \mathrm{M} \text {, } \\
\mathrm{pH}=9)\end{array}$ & Extraction & $68 \%$ \\
\hline & Tasaki (2020) & Hog hair & $\begin{array}{l}\text { Two-step heating process using the thermal } \\
\text { hydrolysis process }\end{array}$ & Extraction & $68 \%$ \\
\hline & Tonin et al. (2006) & Wool & Steam explosion at $220^{\circ} \mathrm{C}$ for $10 \mathrm{~min}$ & Conversion & $18.66 \%$ \\
\hline \multirow[t]{2}{*}{ Biological methods } & Wang et al. (2016) & Wool & $\begin{array}{l}8 \mathrm{M} \text { urea, } 0.165 \mathrm{ml} \text {-cysteine at } 75^{\circ} \mathrm{C} \text { for } 5 \mathrm{~h} \text {, and } \mathrm{pH} \\
=10.5\end{array}$ & Extraction & $72 \%$ \\
\hline & $\begin{array}{l}\text { Alahyaribeik et al. } \\
\text { (2020) }\end{array}$ & Feather & Ultrasonic-assisted enzymolysis & Protein content & $1.73 \pm 0.10 \mathrm{mg} / \mathrm{ml}$ \\
\hline
\end{tabular}

a cross-linked structure through the intermolecular and intramolecular disulfide bonds, which determines its high stability and low solubility (Aluigi et al., 2008b; Shavandi et al., 2017b). The peptide chain of wool keratin consists of an $\alpha$-helix, a $\beta$-sheet, a $\beta$-turn, and a random coil conformation. Its polypeptide chain forms a tortuous cross-linked threedimensional structure by intermolecular disulfide bonds, hydrogen bonds, salt bonds, ester bonds, and Vander Waals forces (Vasconcelos et al., 2008; Wang et al., 2016).

Recently, many researchers have explored the extraction and dissolution of keratins. The related methods and extraction rate results are shown in Table 1. In chemical methods, reducing agents or oxidants are often employed to extract keratin by breaking the disulfide bond of keratin. Physicochemical methods are mostly based on violent reaction conditions, such as hydrothermal (Zoccola et al., 2012), high density steam flashexplosion (HDSF) (Zhao et al., 2012), and steam explosion (Tonin et al., 2006). On the other hand, biological methods primarily incorporate microorganisms and enzymes to treat the wool and degrade the keratin to obtain a keratin macromolecule. Due to the specificity of the enzyme, it can significantly improve the solubility of keratin, but the temperature of this method is demanding, and most of the temperature does not exceed $75^{\circ} \mathrm{C}$. However, the above extraction or dissolution methods have some disadvantages, such as high price, harsh extraction conditions, low extraction rate, or the use of non-environmentally friendly reagents, which restricts wool recycling. In addition, the current methods are mostly traditional heating methods, which are in the form of heat conduction and convection, resulting in a large amount of heat loss (Zhang et al., 2021). Therefore, researchers are focusing on finding a simple, low-cost, green method to extract and dissolve wool keratin. The microwave induction has attracted much attention in recent years and has been successfully applied in many fields such as organic, biological, catalytic, oil recovery, metallurgy, and environmental pollution control (Balu et al., 2012; Rosana et al., 2012; Falciglia et al., 2018; Katsuki et al., 2018; Sarkar et al., 2018). Compared with the conventional (water/oil) heating mechanism, under microwave irradiation, polar substances in the reaction system can convert the absorbed microwave energy into thermal energy, which becomes a miniature "molecular heater", thereby achieving fast, uniform internal heating without temperature gradients. The unique heating mechanism of the microwave greatly increases the possibility of intermolecular collisions, thereby speeding up the reaction rate. Therefore, as a green and efficient microwave radiation technology, it has brought huge influence and opportunities to many chemical fields. Nowadays, there have been reports of microwave induction methods for the extraction of wool keratin. Jou et al. (1999) proved that microwave radiation can penetrate deep into the folding layers of the $\alpha$-helix keratin to destabilize the bonds between the units and make them twirl rapidly. Zoccola et al. (2012) found the method for hydrolysis and extraction of protein material from wool using microwave irradiation in superheated water. In addition, the extraction yield increased from about $10 \%$ to about $60 \%$ in the temperature range of $150-180^{\circ} \mathrm{C}$ for $60 \mathrm{~min}$. It could be seen from published literature reports that in the 
microwave method, a higher extraction temperature was used, and the extraction rate was not significantly improved compared with other methods. Therefore, the microwave induction method still has room for optimization. Under more milder temperature conditions, the structure, crystalline state, and thermal properties of the extracted keratin remain to be studied.

In this paper, a better microwave-induced experimental scheme was obtained, which shortened the extraction time in half and increased the dissolution rate of the wool, compared to conventional thermal induction. Under the same experimental conditions (except microwave power), the effects of the microwave induction (MI) method and conventional thermal induction (CI) method on the size, structure, crystallinity, and thermal stability of the extracted keratin were studied by dynamic light scattering (DLS), total reflection Fourier transform infrared spectroscopy (ATR-FTIR), Raman spectroscopy, X-ray diffraction (XRD), and thermogravimetric analysis (TG) and other corresponding characterization methods. Meaningful comparisons between the MI method and the CI method were carried out.

\section{EXPERIMENT}

\subsection{Raw Materials}

Wool fiber samples (20.1 $\mu \mathrm{m}$ fineness) were provided by Linwo Wool Products (Hebei) Co., Ltd. Urea $\left(\mathrm{CH}_{4} \mathrm{~N}_{2} \mathrm{O}, \mathrm{AR}\right)$ and sodium metabisulfite $\left(\mathrm{Na}_{2} \mathrm{~S}_{2} \mathrm{O}_{5}, \mathrm{AR}\right)$ were provided from Shanghai Maclean Biochemical Technology Co., Ltd. Sodium dodecyl sulfate (SDS, AR) was obtained from J\&K Scientific in Beijing. Sodium hydroxide $(\mathrm{NaOH}, \mathrm{AR})$ was provided from Beijing Chemical Works. Protein standard (MW 10 000-170 000) was provided from Thermo Scientific, deionized (DI) water was used in all experiments.

\subsection{Extraction of Wool Keratin}

\subsubsection{Pretreatment of Wool Fibers}

The wool fibers were first rinsed with running water and dried in a vacuum drier at $100^{\circ} \mathrm{C}$ for $12 \mathrm{~h}$. Then, they were cleaned by an acetone/ethanol (1:1) mixture solvent system in a Soxhlet extraction set for $48 \mathrm{~h}$ to remove fatty matters. Finally, the wool fibers were washed again with DI water and dried again in a vacuum drier at $100^{\circ} \mathrm{C}$ for $12 \mathrm{~h}$ (Zhang et al., 2018). The dried wool fibers were cut to a length of $1-2 \mathrm{~cm}$ and used for solubility experiments.

\subsubsection{Extraction Methods of Wool Keratin}

In this paper, the CI method and the MI method were explored in the process of extracting wool keratin. The optimum extraction conditions were obtained by adjusting the concentration of urea (5-12 M), sodium metabisulfite $(0-0.7 \mathrm{M})$ and SDS (0-2.5 g/L), and the influence of reaction time $(1-5 \mathrm{~h})$, reaction temperature $\left(25-65^{\circ} \mathrm{C}\right)$, and $\mathrm{pH}(5.5-10)$ on the dissolution rate of wool were also studied. The heating method used in the CI method was a water bath method while the MI method was heated by a microwave synthesis system (Mars S, CEM, United States).

The wool keratin solutions prepared by the above two extraction methods are filtered through filter paper, respectively. The filtrate was centrifuged at $10,000 \mathrm{rpm}$ for $5 \mathrm{~min}$, and then the transparent supernatant was collected and placed in a semipermeable membrane with a diameter of $25 \mathrm{~mm}$, length of $400 \mathrm{~mm}$, and nominal molecular weight cut-off value of $7000 \mathrm{Da}$. The dialysis tubes containing supernatant samples were placed into a beaker containing DI water $(5000 \mathrm{ml})$, and the dialysate was replaced every $8 \mathrm{~h}$ until conductivity value is close to $30 \mu \mathrm{S} / \mathrm{cm}$. After dialysis, the purified samples were dried by the freeze-drying method. The obtained keratin was sealed and stored at $4^{\circ} \mathrm{C}$ until used. Keratins prepared by $\mathrm{CI}$ and $\mathrm{MI}$ method, respectively, were designated as $\mathrm{K}-\mathrm{C}$ and $\mathrm{K}-\mathrm{M}$.

\subsubsection{Calculation of Wool Dissolution Rate}

The filtered insoluble matter was washed repeatedly and then dried together in the electric thermostatic drying oven until the mass remains unchanged. The formula of wool dissolution rate is as follows:

$$
S=\frac{m_{1}-m_{2}}{m_{1}} \times 100 \%
$$

where $S(\%)$ is wool dissolution rate, $m_{1}(\mathrm{~g})$ is the initial mass of wool, and $m_{2}(\mathrm{~g})$ is undissolved wool.

\subsection{Characterization}

IR spectra were obtained using an ATR-FTIR spectrophotometer (Nicolet iS 10, Thermo Fisher Scientific, United States) in a scanning frequency range of $400-4000 \mathrm{~cm}^{-1}$ at a constant spectral resolution of $8 \mathrm{~cm}^{-1}$. Raman spectra were obtained with the HORIBA micro-confocal laser Raman spectrometer over a scanning frequency range of $400-1800 \mathrm{~cm}^{-1}$ at a resolution of $1 \mathrm{~cm}^{-1}$. Laser excitation was provided by a HeNe laser operating at $633 \mathrm{~nm}$ output. X-ray diffraction (XRD) was performed on a Rigaku-D/Max-2550 PC diffractometer with $\mathrm{Cu}$ $\mathrm{K} \alpha$ radiation at $40 \mathrm{kV}, 40 \mathrm{~mA}$ from $5-90$ at a rate of $0.03 \mathrm{~cm}^{-1}$. The particle size of wool keratin in an aqueous solution was measured by the dynamic light scattering measurement method (Zetasizer NANO ZS, Malvern Instruments Ltd., United Kingdom). Thermogravimetric analysis (TG) measurements were performed on an SII TG/DTA 6300 using 1-6 mg of the sample under an atmosphere of nitrogen gas. The samples were heated from 30 to $800^{\circ} \mathrm{C}$ at a rate of $10^{\circ} \mathrm{C} / \mathrm{min}$. Molecular weight distribution of keratins in hydrolysate was determined by sodium dodecyl sulfate polyacrylamide gel electrophoresis (SDS-PAGE). Samples were dissolved in a buffer containing SDS, mercaptoethanol, glycerol, and $0.1 \%$ bromophenol blue.

\section{RESULTS AND DISCUSSION}

The structure, size, crystallinity, and thermal stability of natural wool and wool keratins were obtained using a combination of ATR-FTIR, Raman spectroscopy, DLS, XRD, and TGA.

\subsection{Exploration of the Extraction Process}

In this paper, sodium metabisulfite $\left(\mathrm{Na}_{2} \mathrm{~S}_{2} \mathrm{O}_{5}\right)$ was adopted as a reducing agent to break the disulfide bonds of wool fibers. The 

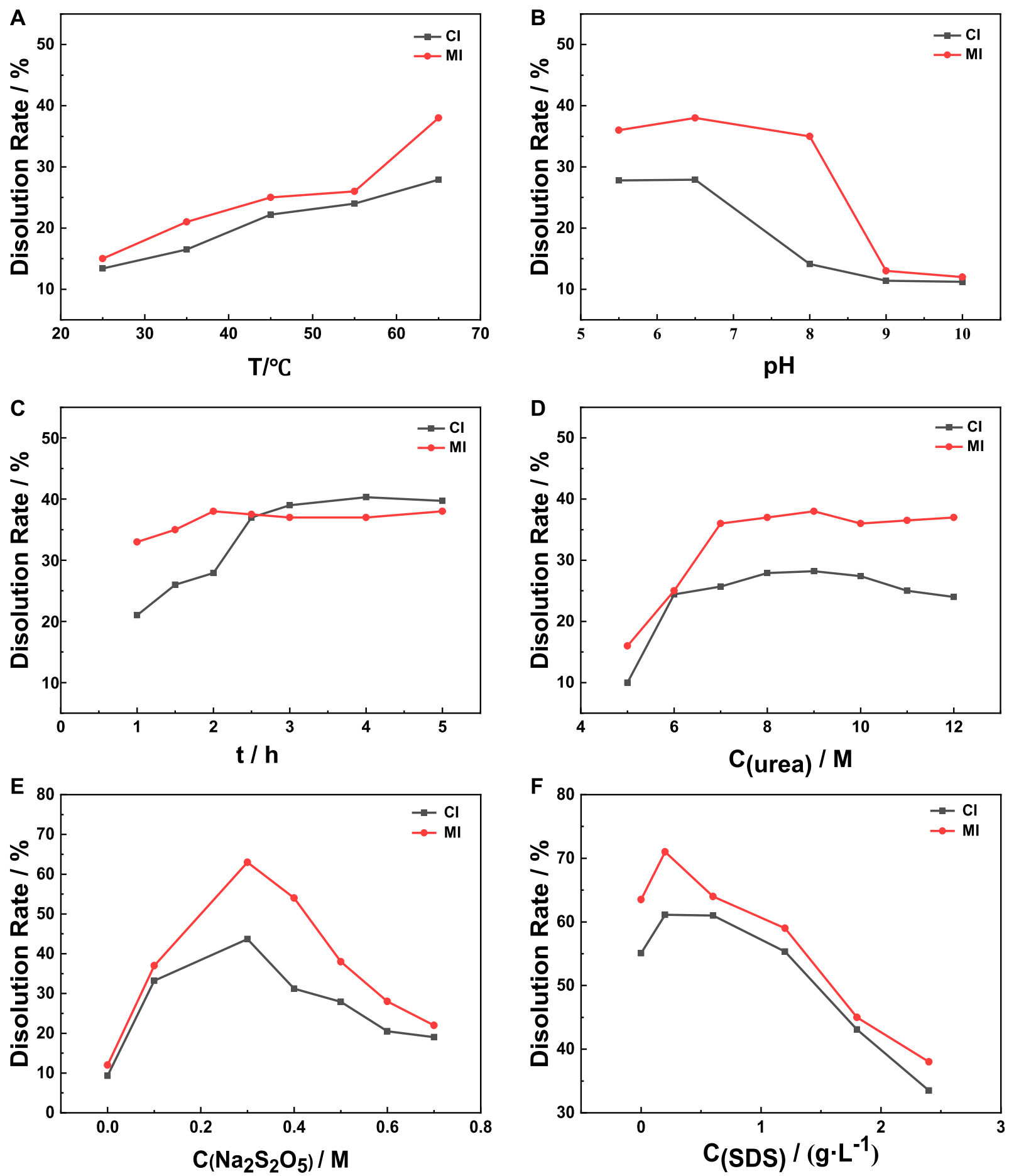

FIGURE 1 | Exploration of the extraction process. (A) $T$, (B) $\mathrm{pH},(\mathbf{C}) t$, (D) $C_{(\text {urea) }}$,

(E) $C_{(\mathrm{Na2S2O5)}}$, (F) $C(\mathrm{SDS})$.

effects of urea, sodium metabisulfite, and SDS on the dissolution rate of wool were explored in the experiment of extracting keratin, and its reaction time, reaction temperature, and $\mathrm{pH}$ were also studied as shown in Figure 1. The initial constant parameter is $8 \mathrm{M}$ urea, $0.5 \mathrm{M}$ sodium metabisulfite at $65^{\circ} \mathrm{C}$ for $2 \mathrm{~h}$ and $\mathrm{pH}=10.5$, and the optimum process was obtained by adjusting different parameters. The optimal concentration of SDS is finally explored after the optimal process is determined.

As the protein will lose part of its chemical and biological activity when it is above $70^{\circ} \mathrm{C}, 65^{\circ} \mathrm{C}$ is selected as the upper limit of the reaction temperature. From Figure 1B, both the MI method and $\mathrm{CI}$ method reach the optimal dissolution rate when the $\mathrm{pH}$ is 


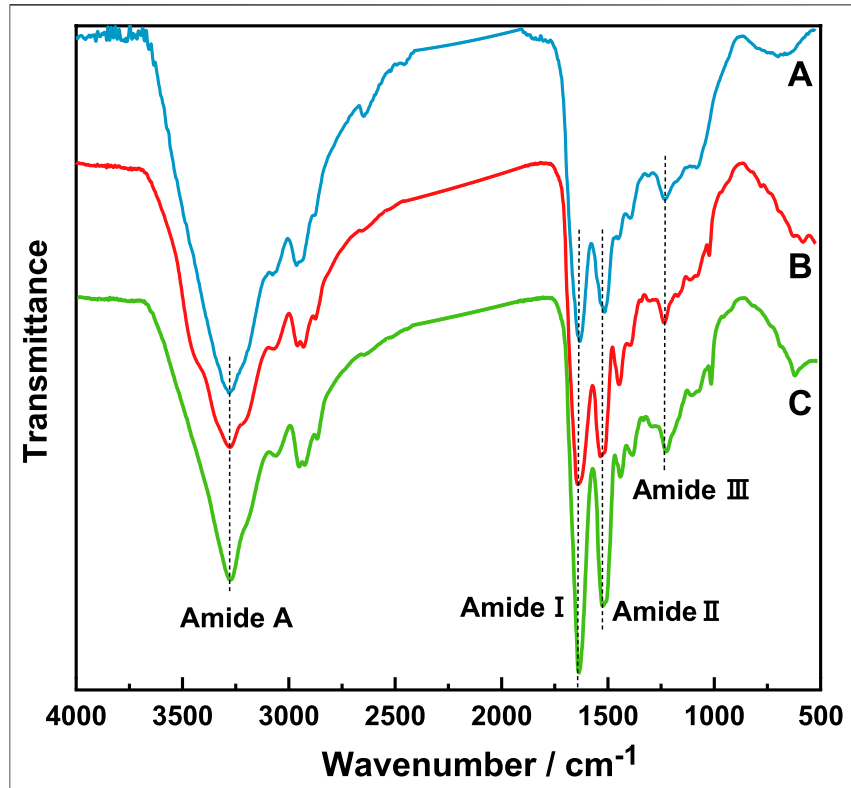

FIGURE 2 | IR spectra of natural wool and wool keratin samples. (A) Natural wool, (B) K-C, (C) K-M.

6.5. The reason for this result may be that the hydroxyl ion $(\mathrm{OH}-)$ in the system reacts with sodium metabisulfite to form sodium sulfite when the $\mathrm{pH}$ value is greater than 7 , which decomposes the reducing agent in the system. Therefore, the damage of sodium metabisulfite on the disulfide bonds of wool fiber is affected, which shows that the dissolution rate of wool decreases significantly.

Urea is used to break the hydrogen bonds between molecules to reduce the intermolecular forces and improve solubility (Shavandi et al., 2017a). Wool swells due to the action of urea, and some of its structure is destroyed. In addition, under microwave conditions, other polar molecules (such as water molecules) in the reaction system absorb microwave energy and vibrate and collide with surrounding molecules (such as urea molecules) to generate heat. At the same time, urea molecules can better contact wool fibers and penetrate the fibers to increase the dissolution rate of wool. When the concentration of urea gradually increases, the swelling degree of wool increases and the dissolution rate increases, but if the concentration is too high, the long-chain macromolecules of wool keratin will be broken, and the dissolution rate of wool decreases due to the decomposition of small peptide chains.

As a surfactant, SDS can be absorbed on the surface of the generated keratin, forming huge micelles, preventing oxygen from reoxidizing the sulfhydryl bonds generated by the cleavage of disulfide bonds, maintaining the reduced state of sulfhydryl groups in the solution, and preventing larger molecular protein precipitates due to its weight. The micellar effect of SDS improves the solubility of keratin and the dissolution reaction of wool shifts to the direction of keratin production (Yamauchi et al., 1996; Shavandi et al., 2017b). When the concentration of SDS increases to $0.2 \mathrm{~g} / \mathrm{L}$, micelles are formed on the surface of keratin, and the dissolution rate of wool no longer increases.
The influence of each parameter on dissolution under two heating methods was compared. The verification experiment was carried out by synthesizing the optimal parameters under the two methods. The dissolution rates of the CI method and the MI method were, respectively, 61 and $71 \%$, and the corresponding traditional heating process was that the treated wool $(2.5 \mathrm{~g})$ and SDS $(0.01 \mathrm{~g})$ were placed in an aqueous solution $(50 \mathrm{ml})$ containing urea $(9 \mathrm{M})$ and $\mathrm{Na}_{2} \mathrm{~S}_{2} \mathrm{O}_{5}(0.3 \mathrm{M})$, adjusted to $\mathrm{pH}$ 6.5 using $\mathrm{NaOH}(5 \mathrm{M})$ and treated by stirring $(500 \mathrm{rpm})$ for $4 \mathrm{~h}$ at $65^{\circ} \mathrm{C}$; the microwave heating process was that the treated wool $(2.5 \mathrm{~g})$ and SDS ( $0.01 \mathrm{~g})$ were put into $50 \mathrm{ml}$ of an aqueous solution containing urea $(9 \mathrm{M})$ and $\mathrm{Na}_{2} \mathrm{~S}_{2} \mathrm{O}_{5}(0.3 \mathrm{M})$, adjusted to pH 6.5 with $\mathrm{NaOH}(5 \mathrm{M})$, and heated by microwave synthesis system (reaction conditions: $400 \mathrm{~W}, 65^{\circ} \mathrm{C}$, and $2 \mathrm{~h}$ ).

\subsection{ATR-FTIR}

The IR spectra of natural wool, K-C and K-M are shown in Figure 2. Absorption peaks of the peptide bonds in wool keratin and natural wool are the same, which indicates that the extracted keratin still retains the peptide chain structure. Peptide bonds (-CONH-) are common in proteinaceous materials. Mid IR absorption spectra of keratins from wool showed characteristic absorption bands due to peptide bonds (-CONH-). The atoms in the peptide bond oscillate forming spectral bands determined as amide A and amide I-III (Wang et al., 2016). The amide A band is due to stretching vibrations of $(\mathrm{N}-\mathrm{H})$ and $(-\mathrm{OH})$ bonds, and the amide A band normally occurs at $3276 \mathrm{~cm}^{-1}$ (Shavandi et al., 2017a). The amide I band comes from $(\mathrm{C}=\mathrm{O})$ vibrations and appears from 1600 to $1700 \mathrm{~cm}^{-1}$. The amide II band is due to $(\mathrm{N}-\mathrm{H})$ deformations as well as stretching $(\mathrm{C}-\mathrm{N})$ vibrations and occurs between $1520-1540 \mathrm{~cm}^{-1}$. The amide III band appears at $1220-1300 \mathrm{~cm}^{-1}$, and is due to stretching vibrations of $(\mathrm{C}-\mathrm{N})$ and $(\mathrm{C}-\mathrm{H})$ and bending vibrations of $(\mathrm{N}-\mathrm{H})$ and $(\mathrm{C}=\mathrm{O})$ (Vasconcelos et al., 2008; Zoccola et al., 2009). The position and strength of the amide band are related to the conformation of keratin (Church et al., 1998).

It can be seen from related reports that characteristic peaks of $\alpha$-helices (1650-1657 $\left.\mathrm{cm}^{-1}\right)$, random coil $\left(1670-1697 \mathrm{~cm}^{-1}\right)$, and $\beta$-sheets $\left(1620-1630 \mathrm{~cm}^{-1}\right)$ are involved in the amide I band (Wang et al., 2016), meantime, characteristic peaks of $\alpha$-helices $\left(1330-1290 \mathrm{~cm}^{-1}\right), \quad \beta$-turns $\left(1295-1270 \mathrm{~cm}^{-1}\right), \quad$ random coil $\left(1270-1250 \mathrm{~cm}^{-1}\right)$, and $\beta$-sheets $\left(1250-1220 \mathrm{~cm}^{-1}\right)$ are involved in the amide III bands (Vasconcelos et al., 2008). Therefore, in order to explore the influence of different extraction methods on the secondary structure of wool keratin, after normalizing the infrared spectrum at $3276 \mathrm{~cm}^{-1}$ (Zhao et al., 2012), a peak fitting was performed. The deconvolutions of amide I and III spectral region for natural wool and wool keratin are shown in Figures 3A-C. The change of the vibration modes of the above three bands is closely related to the secondary structure in natural wool and wool keratins.

Therefore, the relative absorption peak area ratios of these characteristic bands were quantitatively listed in Table 2 . First, it can be found that the secondary structure types of wool keratins prepared by different extraction methods remain unchanged. Furthermore, the ratios of $\beta$-sheet and $\alpha$-helix structures of keratins prepared by K-C and K-M are less than natural wool, 

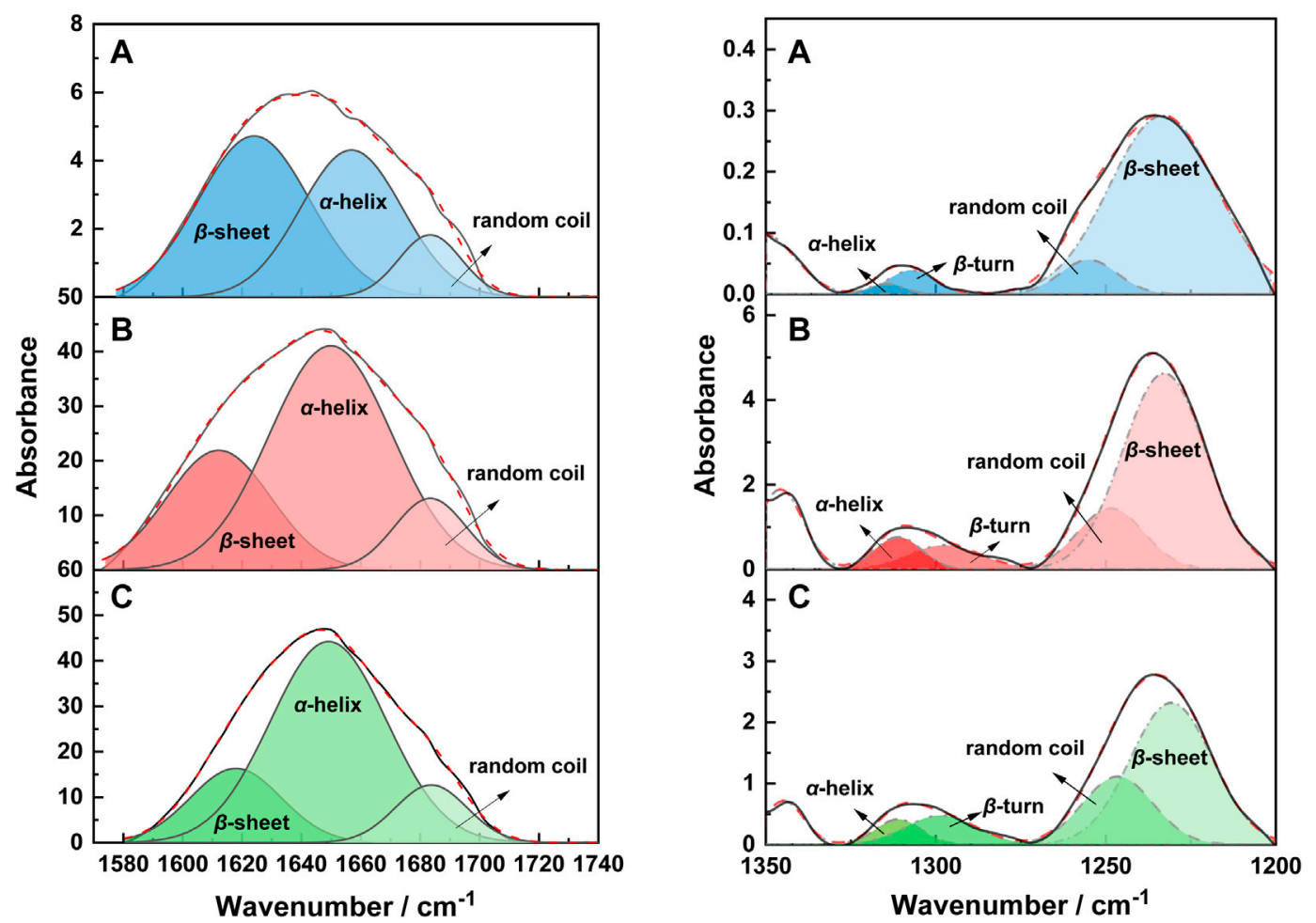

FIGURE 3 | The deconvolution of the amide I and III spectral region of the IR spectra of natural wool (A), K-C (B), and K-M (C).

TABLE 2 | The integral area ratio of the characteristic absorption peaks of the amide I and III band in IR spectra of samples.

\begin{tabular}{|c|c|c|c|c|}
\hline Samples & & $\begin{array}{c}(\beta \text {-sheet }+\alpha \text { - } \\
\text { helix }) / \%\end{array}$ & Random coil/\% & $\beta$-turn $/ \%$ \\
\hline Natural wool & Amide I band & 89.3 & 10.7 & - \\
\hline $\mathrm{K}-\mathrm{C}$ & & 88.6 & 11.4 & - \\
\hline Natural wool & Amide III band & 91.0 & 9.0 & - \\
\hline $\mathrm{K}-\mathrm{C}$ & & 75.4 & 17.2 & 7.4 \\
\hline
\end{tabular}

while the proportion of random rotation structures increases. This implies that the disulfide bonds in natural wool may be destroyed by the CI and MI methods, resulting in the $\beta$-sheet and $\alpha$-helix structures to be destroyed and transformed into random coil structures. It is worth mentioning that the random coil structure in K-M prepared by the MI method is higher than that by the CI method. This suggests that the MI method can greatly destroy the stability of the $\alpha$-helix and the $\beta$-sheet structures, which is beneficial to the extraction of keratin from wool.

\subsection{Raman Spectroscopy}

Raman spectra of natural wool and wool keratins are shown in Figure 4. The amide I band $\left(1650-1680 \mathrm{~cm}^{-1}\right)$ and amide III band $\left(1230-1330 \mathrm{~cm}^{-1}\right)$ are both caused by the skeleton vibrations of the peptide chain. Both are related to the conformation of wool, especially to the $\alpha$-helix/ $\beta$-sheet structures of wool keratin macromolecules (Liu and Yu, 2006). The S-S vibration $\left(490-550 \mathrm{~cm}^{-1}\right)$ is caused by the vibration of cysteine residues (Edwards et al., 1998). The vibrations of amide band and S-S are closely related to the secondary structure of natural wool and wool keratin. Therefore, the two bands are divided into peaks, and integrated quantitative analysis is performed. Relevant results are shown in Table 3.

First, the Raman spectra of each sample were standardized. Standardization is based on the band at $1450 \mathrm{~cm}^{-1}$, which is assigned to the vibration of the amino acid side chain, and its peak area is independent of the vibration of the keratin molecular skeleton. The peak fitting results of the amide I band $\left(1600-1720 \mathrm{~cm}^{-1}\right)$ are shown in Figure 5.

The characteristic peaks of $\alpha$-helix and $\beta$-sheet structures are $1652 \mathrm{~cm}^{-1}$ and $1671 \mathrm{~cm}^{-1}$, respectively (Rosana et al., 2012). It is 

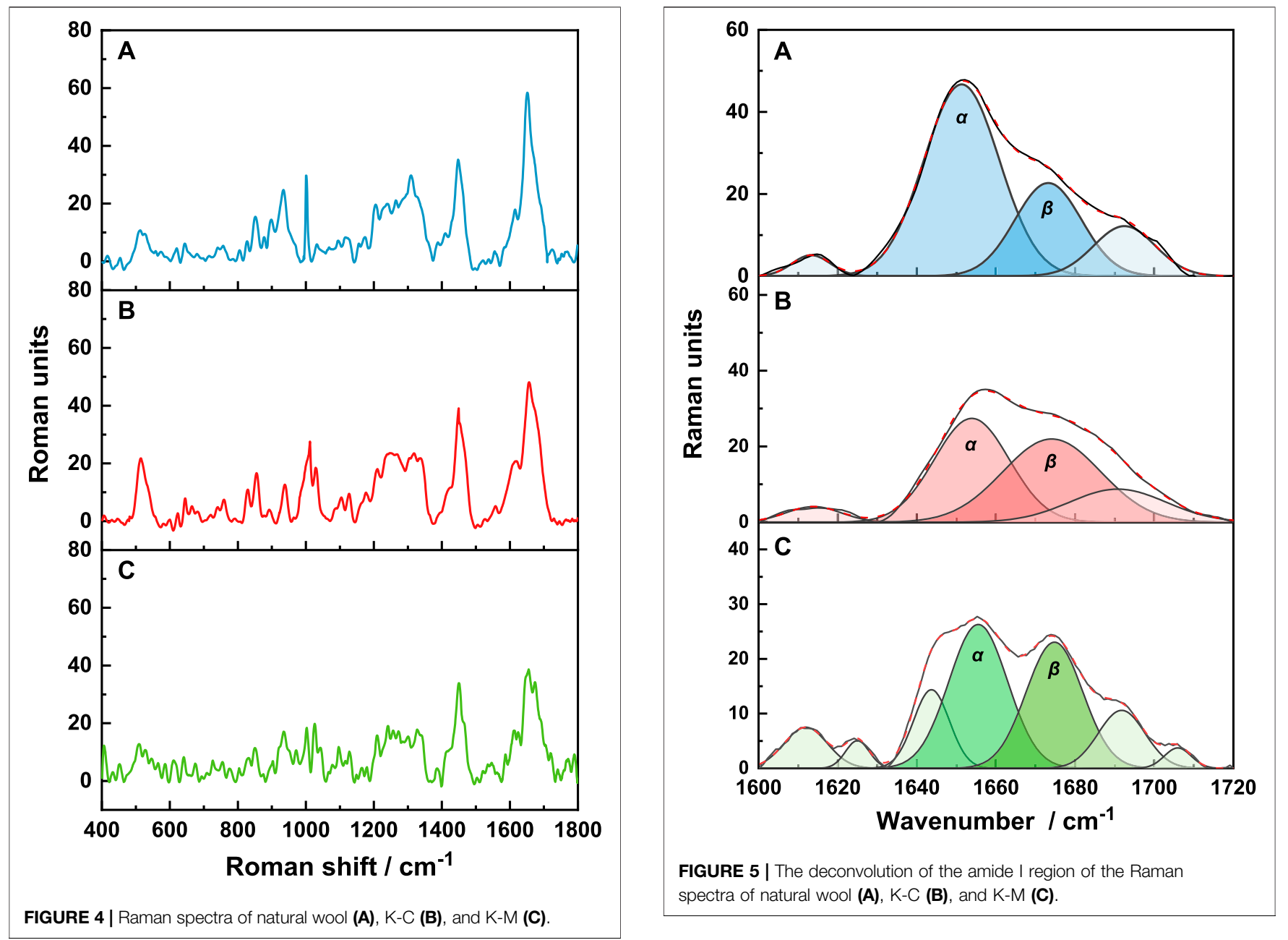

TABLE 3 | The integral area ratios of characteristic peaks in Raman spectra of samples.

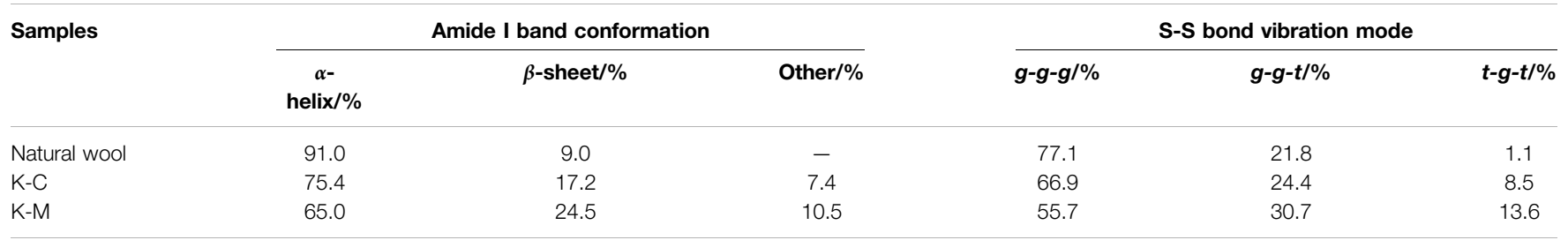

shown that the secondary structures of the three samples are mainly $\alpha$-helix structures. Quantitative analysis of each peak showed that the proportion of $\alpha$-helix structures decreases, while the proportion of $\beta$-sheet structures increases. This indicates that the disulfide bond is opened after reduction, destroying the $\alpha$-helix structure, and transforming it into a $\beta$ sheet structure. Under microwave irradiation, the additional disulfide bonds break, resulting in more $\alpha$-helix structures transformed into $\beta$-sheet structures.

The deconvolution of the S-S region of the Raman spectra is shown in Figure 6. There are three conformations of disulfide bonds in wool: gauche-gauche-gauche $(g-g-g)$, gauche-gauche- trans $(g-g-t)$, and trans-gauche-trans $(t-g-t)$ conformations (Schlucker et al., 2006; Ackermann et al., 2009). Their corresponding Raman spectral peaks are at $512 \mathrm{~cm}^{-1}$, $527 \mathrm{~cm}^{-1}$, and $547 \mathrm{~cm}^{-1}$, respectively. It can be seen from Figure 6 and Table 3 that the extracted wool keratin still contains disulfide bonds, and $g-g-g$ conformation is dominant, which is the most energy-stable conformation in the keratin (Schlucker et al., 2006). The reduction method leads to the destruction of some disulfide bonds in wool, and the stability of the $g-g-g$ conformation decreases, gradually transforming into the $g-g-t$ and $t-g-t$ conformations. Under microwave irradiation, the degree of disulfide bonds damage is greater than that of water 


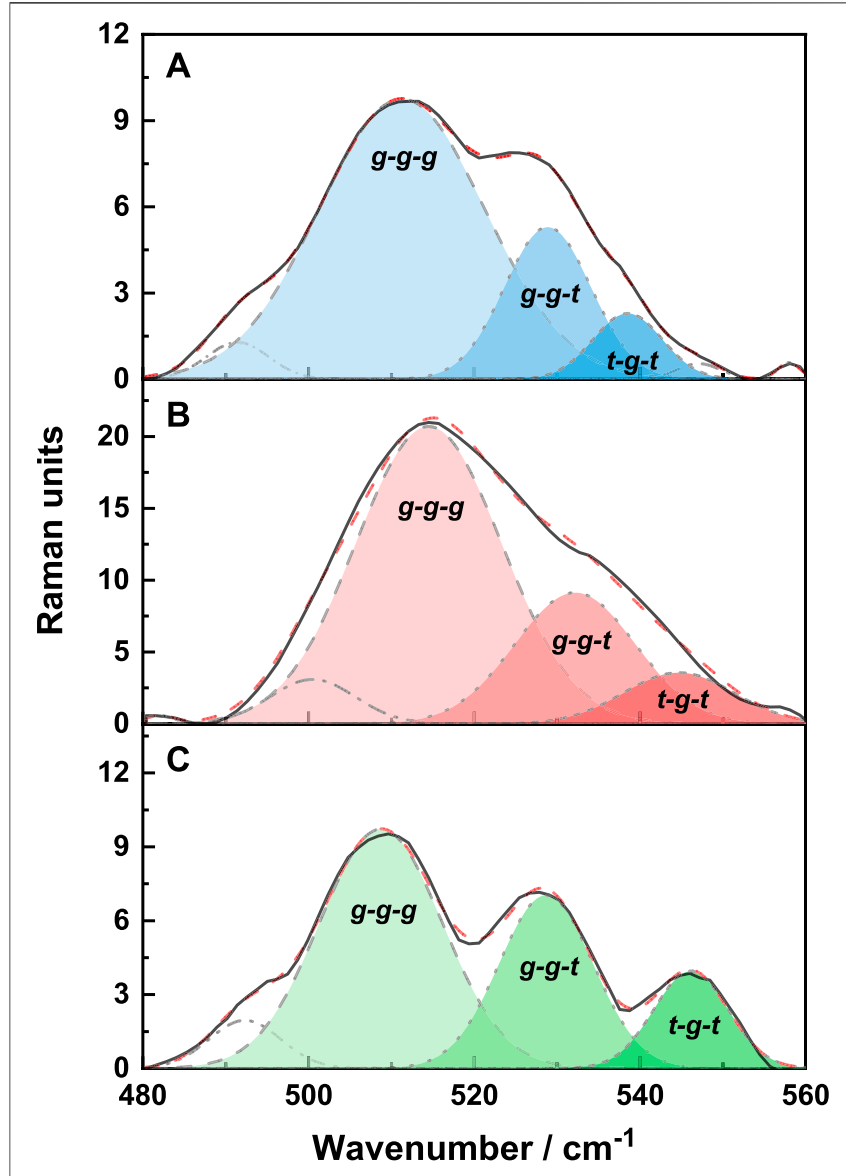

FIGURE 6| The deconvolution of the S-S region of the Raman spectra of natural wool (A), K-C (B), and K-M (C).

bath heating, and the contributions of $g-g-t$ and $t-g-t$ conformational isomers with unstable energy increase significantly. To sum up, the above results show that microwave radiation is more beneficial to breaking of disulfide bonds in natural wool, increases the disorder degree of wool keratin, and improves the extraction rate.
TABLE 4 | Crystallinities of natural wool and wool keratin samples.
Samples

Natural wool

$\mathrm{K}-\mathrm{C}$

$\mathrm{K}-\mathrm{M}$
Crystallinity/\%

29.1

25.3

12.3

\subsection{XRD}

The diffraction peak at $10^{\circ}$ corresponds to the $\alpha$-helix structure of natural wool, while the diffraction peak of the $\beta$-sheet structure appears at $20^{\circ}$ (Xie et al., 2005; Aguayo-Villarreal et al., 2011). Figure 7A shows obvious diffraction peaks, which appear at $5^{\circ}-15^{\circ}$ and $15^{\circ}-35^{\circ}$, corresponding to the $\alpha$-helix and $\beta$-sheet structures, respectively. The intensity of the diffraction peaks also differs due to the different extraction methods. The crystallinity of each sample is obtained by fitting the peak in $5-35^{\circ}$ sections and calculating the area ratio of crystal to amorphous. Take the peak results of natural wool as an example, see Figure 7B.

As shown in Table 4, the crystallinity of natural wool keratin decreases after being treated with the reducing agent, indicating that the crystallinity of natural wool is seriously damaged after reduction. The crystallinity of keratin prepared by microwave irradiation is only $12.3 \%$, which shows that this method can effectively destroy the crystallinity of natural wool. By contrast, the crystallinity of K-C is $25.3 \%$.

\subsection{DLS}

Owing to keratin contains hydrophobic segments, it is dispersed in water to form a suspension. Therefore, the particle size of keratin in water can also indirectly characterize the size of keratin molecules. The particle size and distribution of K-C and K-M in water are shown in Figure 8. The particle sizes of wool keratin prepared by the CI and MI methods are 255 and $142 \mathrm{~nm}$, respectively, indicating that microwave induction is beneficial to obtain keratin with smaller particle sizes. This conclusion proves once again that the MI method is more beneficial to the cleavage of the disulfide bond, and the smaller the particle size of keratin, the more beneficial it is for graft polymerization and further research.
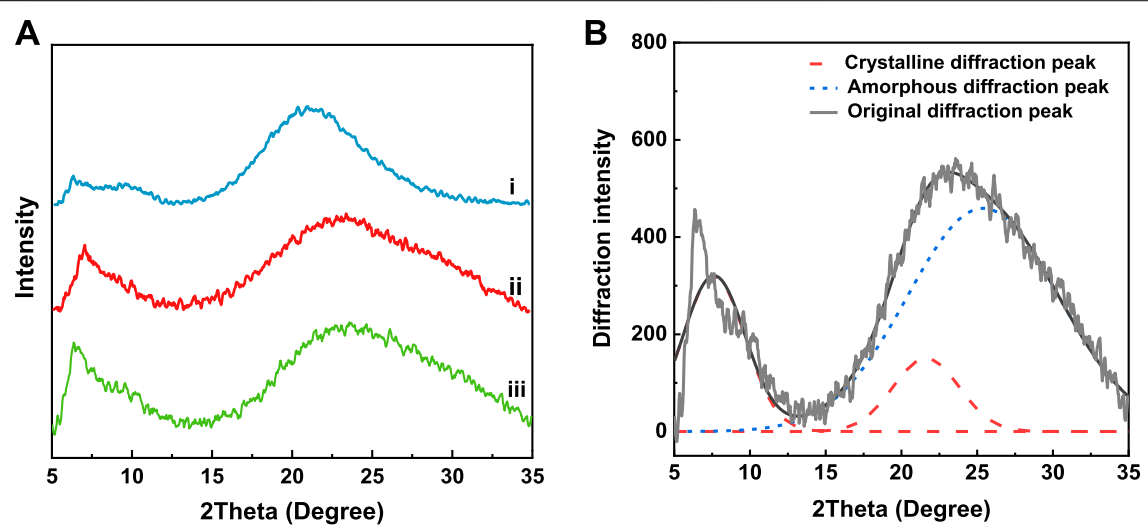

FIGURE 7 | XRD spectrum of samples (A) i: natural wool, ii: K-C, iii: K-M; (B) peak fitting results of natural wool XRD spectrum. 

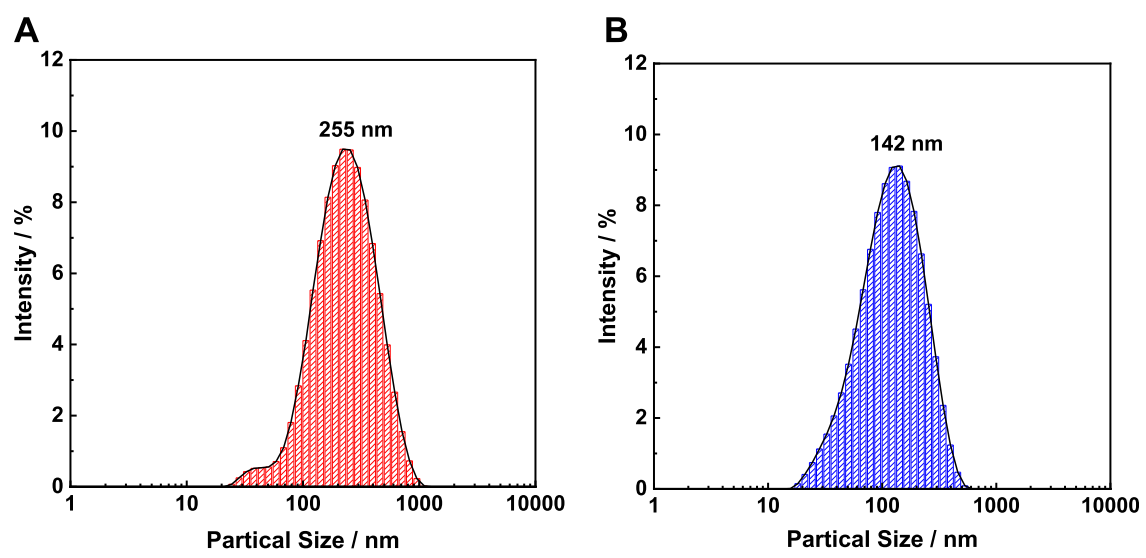

FIGURE 8 | Particle sizes and their distribution of K-C (A) and K-M (B).
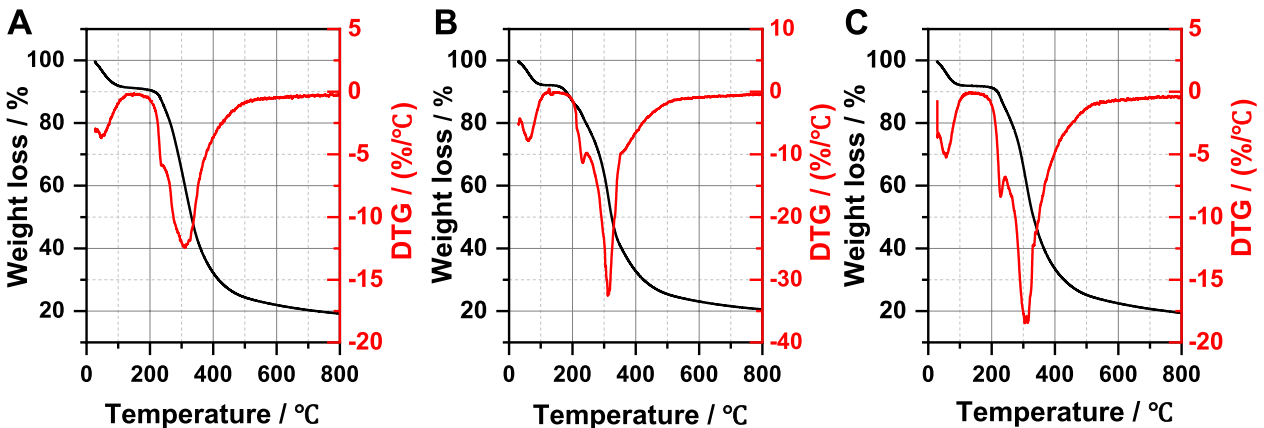

FIGURE 9 | Thermogravimetric analysis curves of natural wool (A), K-C (B), and K-M (C).

TABLE 5 | Thermogravimetric data of natural wool and wool keratin samples.

\begin{tabular}{|c|c|c|c|c|c|}
\hline \multirow[t]{2}{*}{ Samples } & \multicolumn{2}{|c|}{ Thermal decomposition peak } & \multicolumn{3}{|c|}{ Weight loss percentage/\% } \\
\hline & Peak 1 & Peak 2 & $30-150^{\circ} \mathrm{C}$ & $150-250^{\circ} \mathrm{C}$ & $250-800^{\circ} \mathrm{C}$ \\
\hline Natural wool & 234 & 312 & 8.8 & 7.5 & 61.3 \\
\hline $\mathrm{K}-\mathrm{C}$ & 232 & 311 & 7.9 & 6.8 & 60.4 \\
\hline K-M & 228 & 306 & 8.0 & 6.7 & 59.5 \\
\hline
\end{tabular}

\subsection{TG}

The thermal stability of natural wool and wool keratin was investigated by TG and DTG as shown in Figure 9 and Table 5. A three-step decomposition process was observed in all DTG curves. The initial weight loss at about $100^{\circ} \mathrm{C}$ is due to moisture evaporation, and the second and the third weight loss occur in the temperature range from 200 to $500^{\circ} \mathrm{C}$, which is attributed to the lateral chain destruction of wool keratin (Idris et al., 2014). The second weight loss at around $220^{\circ} \mathrm{C}$ is related to the denaturation of the $\alpha$-helix structure. Compared with $\mathrm{K}-\mathrm{C}$ $\left(232^{\circ} \mathrm{C}\right)$ and natural wool $\left(234^{\circ} \mathrm{C}\right), \mathrm{K}-\mathrm{M}$ occurs at a lower temperature $\left(228^{\circ} \mathrm{C}\right)$. The maximum temperature of thermal decomposition appears in this third step weight loss, K-M $\left(306^{\circ} \mathrm{C}\right)$ and $\mathrm{K}-\mathrm{C}\left(311^{\circ} \mathrm{C}\right)$ are lower compared to natural wool $\left(312^{\circ} \mathrm{C}\right)$, probably due to the cleavage of the disulfide bonds during the extraction process of wool keratin (Li and Wang, 2013). In this stage, the weight loss of K-M (59.5\%) is the smallest, indicating that the content of the disulfide bond in K-M is the least, which is due to the large destruction of the disulfide bond by microwave in the extraction process. This result is also evidenced by Raman spectra. It can be seen from the above data that the thermal stability of wool keratin is lower than that of natural wool. Moreover, microwave radiation is more conducive to opening disulfide bonds, destroying the $\alpha$-helix structure, and extracting wool keratin.

\subsection{SDS-PAGE}

SDS-PAGE gel electrophoresis was used to evaluate the molecular weight and distribution of keratins in Figure 10. Several bands are 


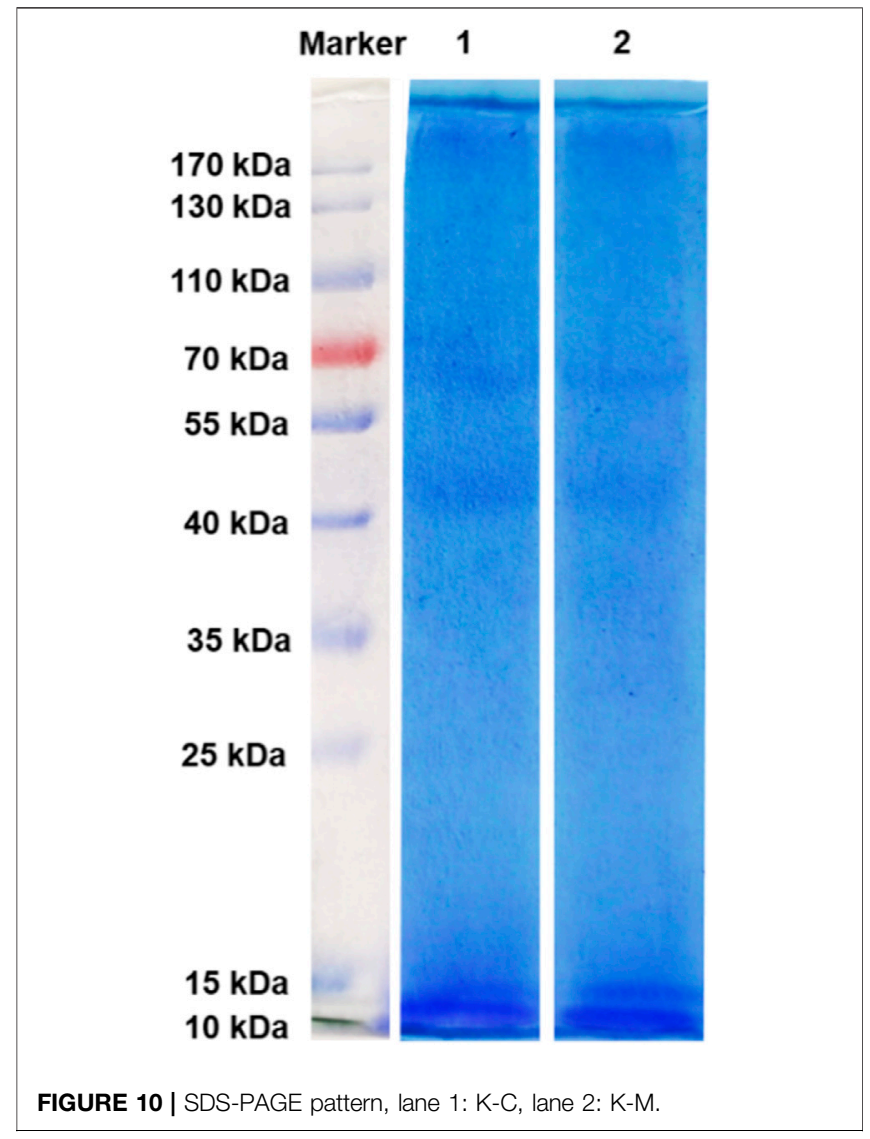

observed at $10,15,44$, and $64 \mathrm{kDa}$ corresponding to $\mathrm{K}-\mathrm{C}$ (Figure 10, lane 1) and K-M (Figure 10, lane 2). Meanwhile, strong bands at $10,15 \mathrm{kDa}$ are clearly observed in both keratins, indicating that the molecular weight of keratin obtained by two extraction methods is consistent. These results are coherent with the previously published reports (Wang et al., 2016; Zhang et al., 2018).

\section{CONCLUSION}

This work provided a green and highly efficient wool keratin by the MI method and provided important guidance to the disposal of wool wastes. Its extraction time is shortened by half, and the

\section{REFERENCES}

Ackermann, K. R., Koster, J., and Schlücker, S. (2009). Conformations and Vibrational Properties of Disulfide Bridges: Potential Energy Distribution in the Model System Diethyl Disulfide. Chem. Phys. 355, 81-84. doi:10.1016/j.chemphys.2008.11.008

Aguayo-Villarreal, I. A., Bonilla-Petriciolet, A., Hernández-Montoya, V., MontesMorán, M. A., and Reynel-Avila, H. E. (2011). Batch and Column Studies of Zn2+ Removal from Aqueous Solution Using Chicken Feathers as Sorbents. Chem. Eng. J. 167, 67-76. doi:10.1016/j.cej.2010.11.107

Alahyaribeik, S., and Ullah, A. (2020). Effects of Ultrasound-Assisted Alkaline Extraction on Antioxidant Activity and Functional Characteristics of Chicken Feather Keratin Peptides. Chemistry Select. 5, 13788-13794. doi:10.1002/slct. 202002887 dissolution rate of the wool is also improved to $71 \%$, which can be used to enhance the sustainable development of keratincontaining waste. The MI method can greatly destroy the stability of the $\alpha$-helix and the $\beta$-sheet structures, and transform them to random coil structures. Meanwhile, it further promotes the transformation of $g-g-g$ conformation to $g$ - $g$ - $t$ and $t$ - $g$ - $t$ conformation, which leads to more disulfide bonds breakage. The crystallinity of keratin prepared by the MI method is only $12.3 \%$, indicating that microwave radiation can effectively destroy the crystallinity of natural wool. Compared with the CI method, the MI method has no significant effect on molecular weight of keratin, whereas this method is beneficial for obtaining keratin with a smaller particle size.

\section{DATA AVAILABILITY STATEMENT}

The original contributions presented in the study are included in the article/Supplementary Material, further inquiries can be directed to the corresponding authors.

\section{AUTHOR CONTRIBUTIONS}

LZ, WD, JC and DW contributed to conception and design of the study. LZ performed the data analysis. WD wrote the first draft of the article. CZ, HL, WL and JZ wrote sections of the article. All authors contributed to article revision, read, and approved the submitted version.

\section{FUNDING}

The financial supports from the National Natural Science Foundation of China (Grant No. 51572293), the Beijing Municipal Education Commission Science and Technology Project, China (Grant No. KM202010012009), the Beijing Institute of Fashion Technology 2021' Practical Training Plan' Project (Grant No. NHFZ20210022/016), the Special Fund for the construction of high-level teachers in Beijing Institute of Fashion Technology, China (Grant No. BIFTXJ201916) and 2022 College Student Innovation and Entrepreneurship Training Project are gratefully acknowledged.

Aluigi, A., Vineis, C., Ceria, A., and Tonin, C. (2008a). Composite Biomaterials from Fibre Wastes: Characterization of Wool-Cellulose Acetate Blends. Composites A: Appl. Sci. Manufacturing 39, 126-132. doi:10.1016/j. compositesa.2007.08.022

Aluigi, A., Vineis, C., Varesano, A., Mazzuchetti, G., Ferrero, F., and Tonin, C. (2008b). Structure and Properties of Keratin/PEO Blend Nanofibres. Eur. Polym. J. 44, 2465-2475. doi:10.1016/j.eurpolymj.2008.06.004

Balu, A. M., Dallinger, D., Obermayer, D., Campelo, J. M., Romero, A. A., Carmona, D., et al. (2012). Insights into the Microwave-Assisted Preparation of Supported Iron Oxide Nanoparticles on Silica-type Mesoporous Materials. Green. Chem. 14, 393-402. doi:10.1039/c1gc16119a

Church, J. S., Corino, G. L., and Woodhead, A. L. (1998). The Effects of Stretching on Wool Fibres as Monitored by FT-Raman Spectroscopy. J. Mol. Struct. 440, 15-23. doi:10.1016/s0022-2860(97)00227-5 
Dias, G. J., Peplow, P. V., McLaughlin, A., Teixeira, F., and Kelly, R. J. (2010). Biocompatibility and Osseointegration of Reconstituted Keratin in an Ovine Model. J. Biomed. Mater. Res. A. 92, 513-520. doi:10.1002/jbm.a.32394

Edwards, H. G. M., Hunt, D. E., and Sibley, M. G. (1998). FT-Raman Spectroscopic Study of Keratotic Materials: Horn, Hoof and Tortoiseshell. Spectrochimica Acta A: Mol. Biomol. Spectrosc. 54, 745-757. doi:10.1016/s1386-1425(98)00013-4

Falciglia, P. P., Roccaro, P., Bonanno, L., De Guidi, G., Vagliasindi, F. G. A., and Romano, S. (2018). A Review on the Microwave Heating as a Sustainable Technique for Environmental Remediation/detoxification Applications. Renew. Sustainable Energ. Rev. 95, 147-170. doi:10.1016/j.rser.2018.07.031

Hill, P., Brantley, H., and Van Dyke, M. (2010). Some Properties of Keratin Biomaterials: Kerateines. Biomaterials 31, 585-593. doi:10.1016/j.biomaterials. 2009.09.076

Idris, A., Vijayaraghavan, R., Rana, U. A., Patti, A. F., and MacFarlane, D. R. (2014). Dissolution and Regeneration of Wool Keratin in Ionic Liquids. Green. Chem. 16, 2857-2864. doi:10.1039/c4gc00213j

Ji, Y., Chen, J., Lv, J., Li, Z., Xing, L., and Ding, S. (2014). Extraction of Keratin with Ionic Liquids from Poultry Feather. Separation Purif. Technology 132, 577-583. doi:10.1016/j.seppur.2014.05.049

Jou, C. J. G., Chen, Y. S., Wang, H. P., Lin, K. S., and Tai, H. S. (1999). Hydrolytic Dissociation of Hog-Hair by Microwave Radiation. Bioresour. Technology 70, 111-113. doi:10.1016/s0960-8524(99)00011-5

Katsuki, H., Choi, E.-K., Lee, W.-J., Hwang, K.-T., Cho, W.-S., Huang, W., et al. (2018). Ultrafast Microwave-Hydrothermal Synthesis of Hexagonal Plates of Hematite. Mater. Chem. Phys. 205, 210-216. doi:10.1016/j.matchemphys.2017. 10.078

Khumalo, M., Sithole, B., and Tesfaye, T. (2020). Valorisation of Waste Chicken Feathers: Optimisation of Keratin Extraction from Waste Chicken Feathers by Sodium Bisulphite, Sodium Dodecyl Sulphate and Urea. J. Environ. Manage. 262, 110329. doi:10.1016/j.jenvman.2020.110329

Li, R., and Wang, D. (2013). Preparation of Regenerated Wool Keratin Films from Wool Keratin-Ionic Liquid Solutions. J. Appl. Polym. Sci. 127, 2648-2653. doi:10.1002/app.37527

Liu, H., and Yu, W. (2006). Study of the Structure Transformation of Wool Fibers with Raman Spectroscopy. J. Appl. Polym. Sci. 103, 1-7. doi:10.1002/app.23862

Mori, H., and Hara, M. (2018). Transparent Biocompatible Wool Keratin Film Prepared by Mechanical Compression of Porous Keratin Hydrogel. Mater. Sci. Eng. C 91, 19-25. doi:10.1016/j.msec.2018.05.021

Nakamura, A., Arimoto, M., Takeuchi, K., and Fujii, T. (2002). A Rapid Extraction Procedure of Human Hair Proteins and Identification of Phosphorylated Species. Biol. Pharm. Bull. 25, 569-572. doi:10.1248/bpb.25.569

Poole, A. J., Lyons, R. E., and Church, J. S. (2011). Dissolving Feather Keratin Using Sodium Sulfide for Bio-Polymer Applications. J. Polym. Environ. 19, 995-1004. doi:10.1007/s10924-011-0365-6

Rosana, M. R., Tao, Y., Stiegman, A. E., and Dudley, G. B. (2012). On the Rational Design of Microwave-Actuated Organic Reactions. Chem. Sci. 3, 1240. doi:10. $1039 / \mathrm{c} 2 \mathrm{sc} 01003 \mathrm{~h}$

Sarkar, S., Yang, J., Tan, L. Z., Rappe, A. M., and Kronik, L. (2018). Molecule-Adsorbed Topological Insulator and Metal Surfaces: A Comparative First-Principles Study. Chem. Mater. 30, 1849-1855. doi:10.1021/acs.chemmater.7b03176

Schlücker, S., Liang, C., Strehle, K. R., DiGiovanna, J. J., Kraemer, K. H., and Levin, I. W. (2006). Conformational Differences in Protein Disulfide Linkages between normal Hair and Hair from Subjects with Trichothiodystrophy: A Quantitative Analysis by Raman Microspectroscopy. Biopolymers 82, 615-622. doi:10.1002/bip.20515

Shavandi, A., Carne, A., Bekhit, A. A., and Bekhit, A. E.-D. A. (2017a). An Improved Method for Solubilisation of Wool Keratin Using Peracetic Acid. J. Environ. Chem. Eng. 5, 1977-1984. doi:10.1016/j.jece.2017.03.043

Shavandi, A., Silva, T. H., Bekhit, A. A., and Bekhit, A. E.-D. A. (2017b). Keratin: Dissolution, Extraction and Biomedical Application. Biomater. Sci. 5, 1699-1735. doi:10.1039/c7bm00411g
Tasaki, K. (2020). A Novel thermal Hydrolysis Process for Extraction of Keratin from Hog Hair for Commercial Applications. Waste Management 104, 33-41. doi:10.1016/j.wasman.2019.12.042

Tonin, C., Aluigi, A., Vineis, C., Varesano, A., Montarsolo, A., and Ferrero, F. (2007). Thermal and Structural Characterization of Poly(ethylene-Oxide)/keratin Blend Films. J. Therm. Anal. Calorim. 89, 601-608. doi:10.1007/s10973-006-7557-7

Tonin, C., Zoccola, M., Aluigi, A., Varesano, A., Montarsolo, A., Vineis, C., et al. (2006). Study on the Conversion of Wool Keratin by Steam Explosion. Biomacromolecules 7, 3499-3504. doi:10.1021/bm060597w

Vasconcelos, A., Freddi, G., and Cavaco-Paulo, A. (2008). Biodegradable Materials Based on Silk Fibroin and Keratin. Biomacromolecules 9, 1299-1305. doi:10. 1021/bm7012789

Wang, K., Li, R., Ma, J. H., Jian, Y. K., and Che, J. N. (2016). Extracting Keratin from Wool by Using L-Cysteine. Green. Chem. 18, 476-481. doi:10.1039/ c5gc01254f

Wu, P., Dai, X., Chen, K., Li, R., and Xing, Y. (2018). Fabrication of Regenerated Wool Keratin/polycaprolactone Nanofiber Membranes for Cell Culture. Int. J. Biol. Macromolecules 114, 1168-1173. doi:10.1016/j.ijbiomac.2018.03.157

Xie, H., Li, S., and Zhang, S. (2005). Ionic Liquids as Novel Solvents for the Dissolution and Blending of Wool Keratin Fibers. Green. Chem. 7, 606-608. doi:10.1039/b502547h

Yamauchi, K., Yamauchi, A., Kusunoki, T., Kohda, A., and Konishi, Y. (1996). Preparation of Stable Aqueous Solution of Keratins, and Physiochemical and Biodegradational Properties of Films. J. Biomed. Mater. Res. 31, 439-444. doi:10.1002/(sici)1097-4636(199608)31:4<439:aid-jbm1>3.0.co;2-m

Zhang, L., DuWang, W. D., Wang, D., Wang, F., Fang, K., Yu, J., et al. (2021). Syntheses of Polycarboxylate Superplasticizers: Microwave Induction versus Conventional thermal Induction. Composites B: Eng. 207, 108560. doi:10.1016/ j.compositesb.2020.108560

Zhang, N., Wang, Q., Yuan, J., Cui, L., Wang, P., Yu, Y., et al. (2018). Highly Efficient and Eco-Friendly Wool Degradation by L-Cysteine-Assisted Esperase. J. Clean. Prod. 192, 433-442. doi:10.1016/j.jclepro.2018.05.008

Zhao, W., Yang, R., Zhang, Y., and Wu, L. (2012). Sustainable and Practical Utilization of Feather Keratin by an Innovative Physicochemical Pretreatment: High Density Steam Flash-Explosion. Green. Chem. 14, 3352-3360. doi:10. $1039 / \mathrm{c} 2 \mathrm{gc} 36243 \mathrm{k}$

Zoccola, M., Aluigi, A., Patrucco, A., Vineis, C., Forlini, F., Locatelli, P., et al. (2012). Microwave-assisted Chemical-free Hydrolysis of Wool Keratin. Textile Res. J. 82, 2006-2018. doi:10.1177/0040517512452948

Zoccola, M., Aluigi, A., and Tonin, C. (2009). Characterisation of Keratin Biomass from Butchery and Wool Industry Wastes. J. Mol. Struct. 938, 35-40. doi:10. 1016/j.molstruc.2009.08.036

Conflict of Interest: The authors declare that the research was conducted in the absence of any commercial or financial relationships that could be construed as a potential conflict of interest.

Publisher's Note: All claims expressed in this article are solely those of the authors and do not necessarily represent those of their affiliated organizations, or those of the publisher, the editors, and the reviewers. Any product that may be evaluated in this article, or claim that may be made by its manufacturer, is not guaranteed or endorsed by the publisher.

Copyright (c) $2022 \mathrm{Du}$, Zhang, Zhang, Cao, Wang, Li, Li and Zeng. This is an openaccess article distributed under the terms of the Creative Commons Attribution License (CC BY). The use, distribution or reproduction in other forums is permitted, provided the original author(s) and the copyright owner(s) are credited and that the original publication in this journal is cited, in accordance with accepted academic practice. No use, distribution or reproduction is permitted which does not comply with these terms. 